\title{
Synthesis and electrochemical study of some novel alkynylferrocene derivatives
}

\author{
Rahman Hosseinzadeh $^{a^{*}}$, Reza Ojani ${ }^{b}$ and Leila Shabani ${ }^{a}$
}

${ }^{a}$ Department of Organic Chemistry, Faculty of Chemistry, University of Mazandaran, Babolsar, Iran

${ }^{b}$ Electroanalytical Chemical Research Laboratory, Faculty of Chemistry, University of Mazandaran, Babolsar, Iran

\section{CHRON I C LE ABSTRACT}

Article history:

Received March 27, 2013

Received in Revised form

August 27, 2013

Accepted 19 October 2013

Available online

31 October 2013

\section{Keywords:}

Ferrocene derivatives

Sonogashira reaction

Cyclic voltammetry

Alkynylferrocenes

\begin{abstract}
Ferrocene and their derivatives are well-known redox active materials and were extensively used by construction of modified electrodes for the design of electrochemical sensors and biosensors. Substituent derivatization of ferrocene offers the prospect of controlling ferrocene moiety properties such as solubility, stability, reversibility of oxidation wave (important for their role as an electron transfer mediator) and oxidation potential, which is critical in the electrochemical determination of biological compounds. A new series of rigid alkynylferrocene including of 2-ferrocenylethynyl fluoren (3a), 2-ferrocenylethynyl fluoren-9-one (3b), 4ferrocenylethynyl aniline (3c) and 3-ferrocenylethynyl-1-trifluoromethyl benzene (3d) have been prepared in good yields by Sonogashira coupling reaction. All products were characterized by ${ }^{1} \mathrm{H}$ and ${ }^{13} \mathrm{C}$ NMR, FT-IR, and elemental analysis. The redox chemistry of these compounds has been investigated by cyclic voltammetry. The half-wave potential of the terminal ferrocenyl moieties increases progressively in the order of $\mathbf{3 c}<\mathbf{3 a}<\mathbf{3} \mathbf{b}<\mathbf{3 d}$, which is consistent with the electron density on the ferrocenyl unit.
\end{abstract}

\section{Introduction}

In recent years, the synthesis and electrochemical investigation of redox active compounds has found wide application in electrochemistry ${ }^{1}$. For example, ferrocenyl and multiferrocenyl systems have been used as mediators in amperometric biosensors ${ }^{2-3}$ as redox sensors for molecular recognition ${ }^{4-8}$, as building blocks in polymers ${ }^{9-12}$ or as coatings to modify electrode surfaces ${ }^{13-16}$. Electrochemical techniques have been particularly investigated for determining the concentration of biologically and clinically important compounds. In electrochemical methods an applied potential is used between reference and working electrodes for oxidation or reduction of an electroactive species, for example ferrocene derivatives ${ }^{17-22}$.

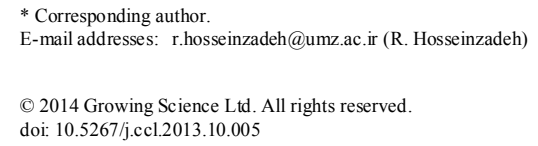


Ferrocenylacetylenes constitute an interesting class of ferrocene derivatives since they may serve as starting materials for the construction of more complex organometallics ${ }^{23-25}$. Sonogashira coupling, the reaction of terminal alkynes with aryl or alkenyl halides is the most straightforward and powerful method for the synthesis of aryl and alkenyl substituted acetylenes ${ }^{26-28}$. This method has been extensively studied and frequently used as a key in the synthesis of polymers, pharmaceuticals, liquid crystals, optical or electronic materials ${ }^{27-28,29}$.

In this paper, we report the preparation of some ferrocene derivatives by Sonogashira coupling reaction of ethynylferroce with various aryl halides (Scheme 1). The electrochemical properties of the resulting ferrocene derivatives are investigated.

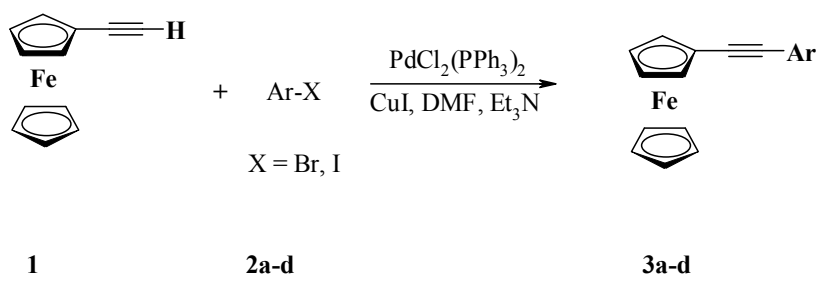

Scheme 1: Synthesis of alkynylferrocenes by Sonogashira reaction

\section{Results and Discussion}

\subsection{Synthesis}

Coupling reaction of ethynylferrocene with aryl halides in the presence of palladium complex, copper iodide and triethyl amine, is used for preparation of internal alkynylferrocenes. The results are summarized in Table 1.

Table 1 Preparation of internal alkynylferrocenes by Sonogashira reaction ${ }^{\mathrm{a}}$

Entry Ary halides

${ }^{\mathrm{a}}$ General conditions: $1.0 \mathrm{mmol}$ of aryl halides, $1.3 \mathrm{mmol}$ of ethynylferrocene, $\mathrm{PdCl}_{2}\left(\mathrm{PPh}_{3}\right)_{2}(29 \mathrm{mg})$ and $\mathrm{CuI}(7.6 \mathrm{mg})$ in DMF and $\mathrm{N}\left(\mathrm{C}_{2} \mathrm{H}_{5}\right)_{3}$ at reflux temperature. ${ }^{\mathrm{b}}$ Isolated yield. Products were characterized by spectroscopic data (IR, $\left.{ }^{1} \mathrm{H} \&{ }^{13} \mathrm{C} N \mathrm{NM}\right)$ and elemental analysis. 
As can be seen from Table 1, aryl halides with electron releasing and electron withdrawing groups could be successfully coupled with ethynylferrocene. In the first step, alkynylferrocenes with fluorene and fluorenone moieties (3a and $\mathbf{3 b}$ ) are prepared by the Sonogashira reaction of ethynylferrocene with 2-bromofluorene (2a) and 2-bromofluorenone (2b). The coupling reaction was preceded very well and products were obtained in good yields (Table 1, entries 1-2). When aryl halide with electron withdrawing group, such as trifluoromethyl group reacted with ethynylferrocene under the same reaction conditions, a very good yield of the coupling product (3d) was obtained (Table 1, entry 4). However, when electron releasing substituted aryl halide $\mathbf{2 c}$ applied in this reaction, only moderate yield of the corresponding alkynylferrocene $\mathbf{3 c}$ was obtained (Table 1, entry 3 ).

\subsection{Cyclic voltammetry study}

In this study, the electrochemical characteristic of synthesized compounds has been investigated using cyclic voltammetry (CV) method by recording their cyclic voltammograms in dichloromethane in the presence of tetrabuthylammonium chloride at the surface of glassy carbon (GC) electrode. Typical cyclic voltammograms related to 2-ferrocenylethynyl fluoren-9-one (3b) has been shown in Fig. 1.

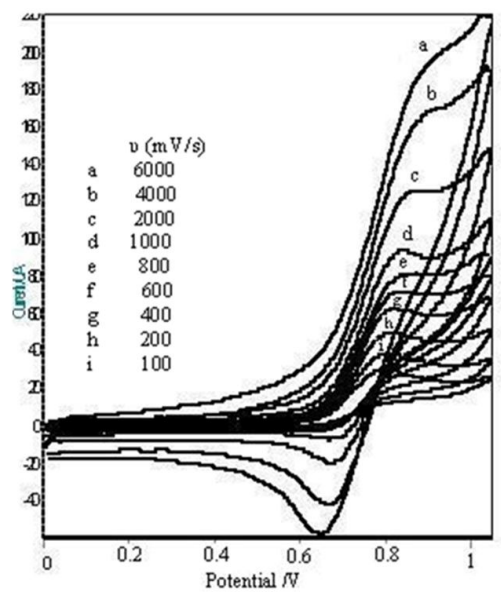

Fig. 1. Cyclic voltammograms of $1 \mathrm{mM}$ of 2-ferrocenylethynyl fluoren-9-one (3b) in $0.25 \mathrm{M}(\mathrm{n}-\mathrm{Bu})_{4} \mathrm{NCl}$ in $\mathrm{CH}_{2} \mathrm{Cl}_{2}$ solvent at various scan rates at the surface of glassy carbon (GC) electrode.

Other compounds (3a, $\mathbf{3 c}$ and $\mathbf{3 d})$ show the similar cyclic voltammograms. As can be seen at the proper potential scan rate, generally these compounds exhibit one forward peak relating the oxidation of ferrocene moiety to ferrocinium form and one reverse peak relating the reduction of ferrocinium to ferrocene moiety.

Some electrochemical characteristic data of these derivatives are summarized in the Table 2. According to this data and with notice to $\Delta \mathrm{E}_{\mathrm{p}}$ values, it is clear, from the view point of electrochemical reversibility, the compound $\mathbf{3 a}$ is the most reversible compound compared to the others. Also order values of $E_{1 / 2}$, half wave potential, as $E_{1 / 2}(\mathbf{3 d})>E_{1 / 2}(\mathbf{3 b})>E_{1 / 2}(\mathbf{3 a})>E_{1 / 2}(\mathbf{3 c})$ show a logical process that with notice to presence of electron withdrawing groups on the $\mathbf{3 d}$ and $\mathbf{3 b}$ molecules and electron releasing group on the $\mathbf{3 c}$ and $\mathbf{3 a}$ derivatives, it is acceptable. On the other hand, one interested point is the absence of reverse peak (cathodic peak) at low potential scan rate for all these derivatives. In fact, at the low potential scan rates, for forward oxidative product exists an enough time to contribute in a chemical follow up reaction (probably an intramolecular reaction). But at higher potential scan rates, there is not enough time to occur a reaction due to decrease the time window of the voltammetric method. Thus the cathodic peak appears in the reverse scan at high potential scan rates. Previously, we observed this behavior for acetylferrocene derivative and used this compound as an electrocatalyst for electrocatalytic oxidation and determination of hydrazine ${ }^{30}$. It is clear that the derivative with highest potential scan rate to show the cathodic peak has an oxidative product with the highest reactivity compared to the others. Therefore, oxidative products of $\mathbf{3 c}$ and $\mathbf{3 d}$ 
needing highest potential scan rate of $2000 \mathrm{mV} / \mathrm{s}$ must be recognized as molecules with highest reactivity.

Table 2 Some electrochemical characteristic data for synthesized ferrocene derivatives.

\begin{tabular}{llllll}
\hline Derivatives & $\mathrm{E}_{\mathrm{na}}(\mathrm{V})^{\mathrm{a}}$ & $\mathrm{E}_{\mathrm{nc}}(\mathrm{V})^{\mathrm{b}}$ & $\mathrm{E}_{\mathrm{n}}(\mathrm{V}) \Delta$ & $\mathrm{E}_{12}(\mathrm{~V})$ & $\mathrm{v}\left(\mathrm{mV} \mathrm{s}^{-1}\right)^{\mathrm{c}}$ \\
\hline 3a & 0.800 & 0.685 & 0.115 & 0.742 & 800 \\
$\mathbf{3 b}$ & 0.840 & 0.698 & 0.142 & 0.769 & 1000 \\
3c & 0.810 & 0.600 & 0.210 & 0.705 & 2000 \\
3d & 0.880 & 0.680 & 0.180 & 0.780 & 2000 \\
\hline
\end{tabular}

${ }^{a} \mathrm{E}_{\mathrm{pa}}$ : Anodic peak potential; ${ }^{b} \mathrm{E}_{\mathrm{pc}}$ : Cathotic peak potential; ${ }^{\mathrm{c}} \mathrm{v}$ : Required potential scan rate to observe reverse peak

\section{Conclusions}

A new series of rigid alkynylferrocene (3a-d) have been prepared in good yields by Sonogashira coupling reaction. The redox chemistry of these compounds has been investigated by cyclic voltammetry. The half-wave potential of the terminal ferrocenyl moieties increases progressively in the order of $\mathbf{3} \mathbf{c}<\mathbf{3} \mathbf{a}<\mathbf{3} \mathbf{b}<\mathbf{3 d}$, which is consistent with the electron density on the ferrocenyl unit. According to electrochemical studies, from the view point of electrochemical reversibility, the compound $\mathbf{3 a}$ is the most reversible compound compared to the others. In addition, these compounds have great potential for the electrocatalytic determination of many important biological active compounds even at real samples.

\section{Acknowledgements}

Financial support of this work from the research council of University of Mazandaran is gratefully acknowledged.

\section{Experimental}

\subsection{Materials and equipment}

All reactions were carried out under argon with the use of standard inert atmosphere and Schlenk techniques. Infrared spectra (IR) were recorded on a Bruker water 22 spectrometer using $\mathrm{KBr}$ pellets. NMR spectra were obtained at 500 (300) MHz using BrukerAvance DRX spectrometer in $\mathrm{CDCl}_{3}$ as solvent and tetramethylsilane (TMS) as an internal standard. Melting points were measured with Electro Thermal 9100. Elemental analyses were performed by LECO $600 \mathrm{CHN}$ Elemental Analyzer. The electrochemical experiments were carried out using a Potentiostat/Galvanostat (BHP 2061-C Electrochemical Analysis System, Behpajoh, Iran) coupled with a Pentium IV personal computer connected to a HP laser jet $6 \mathrm{~L}$ printer. Ethynylferrocene was prepared according to known procedure 22, 31 from acetyl ferrocene. According to the literature, ethynylferrocene has a reversible electrochemical behavior showing an $\mathrm{E}_{1 / 2}$ (half wave potential) about $0.5 \mathrm{~V} / \mathrm{Ag} / \mathrm{AgCl}$ in an aqueous solution $^{22}$.

\subsection{General procedure}

Preparation of alkynylferrocenes:

To a stirred solution of aryl halides $(1.0 \mathrm{mmol})$ and ethynylferrocene $(1.2 \mathrm{mmol})$ in $\mathrm{Et}_{3} \mathrm{~N}(5 \mathrm{~mL})$ and DMF $(5 \mathrm{~mL})$ were added $\mathrm{PdCl}_{2}\left(\mathrm{PPh}_{3}\right)_{2}(29 \mathrm{mg})$ and $\mathrm{CuI}(7.6 \mathrm{mg})$ and the resulting mixture was stirred at reflux temperature for specified time (Table 1). The progress of the reaction was monitored by TLC. After addition of $200 \mathrm{~mL}$ of $\mathrm{H}_{2} \mathrm{O}$ and stirring for $30 \mathrm{~min}$, the resulting crude product was filtered. The resulting raw material was dissolved in $\mathrm{CH}_{2} \mathrm{Cl}_{2}$, then washed with diluted $\mathrm{HCl}$ and saturated $\mathrm{NaCl}$ solution. After drying with $\mathrm{MgSO}_{4}$ and solvents removal, the crude products was purified by column chromatography on silica gel using hexane- $\mathrm{CH}_{2} \mathrm{Cl}_{2}$ (for $\mathbf{3 a}, \mathbf{3 b}$ an 3d) and EtOAc$\mathrm{CH}_{2} \mathrm{Cl}_{2}$ (for $3 \mathbf{c}$ ) as eluent to afford the corresponding internal alkynylferrocenes. 


\subsection{Physical and Spectral Data}

2-Ferrocenylethynyl-9H-fluoren (3a): Orange solid; mp: $160-162{ }^{\circ} \mathrm{C}$. IR: $v\left(\mathrm{~cm}^{-1}\right)=745,1380,2203$ $(\mathrm{C} \equiv \mathrm{C}) .{ }^{1} \mathrm{H}$ NMR $\left(500 \mathrm{MHz}, \mathrm{CDCl}_{3}\right): \delta(\mathrm{ppm})=3.92(\mathrm{~s}, 2 \mathrm{H}), 4.20-4.30$ (pseudo s, $\left.7 \mathrm{H}\right), 4.55(\mathrm{~s}, 2 \mathrm{H})$, 7.27-7.79 (m, 7H). ${ }^{13} \mathrm{C}$ NMR $\left(125 \mathrm{MHz}, \mathrm{CDCl}_{3}\right): \delta(\mathrm{ppm})=36.73,65.50,68.84,70.03,71.43,86.45$, $88.26,119.72,120.08,122.01,125.07,126.89,126.98,127.96,130.27,141.20,141.30,143.16$, 143.50. Anal. Calcd for $\mathrm{C}_{25} \mathrm{H}_{18} \mathrm{Fe}: \mathrm{C}, 80.23 ; \mathrm{H}, 4.85$. Found: $\mathrm{C}, 80.53 ; \mathrm{H}, 4.68$.

2-Ferrocenylethynyl fluoren-9-one (3b): Red solid; mp: $147-148{ }^{\circ} \mathrm{C}$. IR: $v\left(\mathrm{~cm}^{-1}\right)=750,1602$, $1712(\mathrm{C}=\mathrm{O}), 2201(\mathrm{C} \equiv \mathrm{C}) .{ }^{1} \mathrm{H}$ NMR $\left(500 \mathrm{MHz}, \mathrm{CDCl}_{3}\right): \delta(\mathrm{ppm})=4.20-4.30$ (pseudo $\left.\mathrm{s}, 7 \mathrm{H}\right), 4.54(\mathrm{~s}$, $2 \mathrm{H}), 7.30-7.76(\mathrm{~m}, 7 \mathrm{H}) .{ }^{13} \mathrm{C} \mathrm{NMR}\left(125 \mathrm{MHz}, \mathrm{CDCl}_{3}\right): \delta(\mathrm{ppm})=64.62,69.04,70.00,71.48,85.03$, $90.51,120.20,120.45,124.36,124.88,127.02,129.12,134.16,134.27,134.81,137.19,142.94$, 144.07, 193.11. Anal. Calcd for $\mathrm{C}_{25} \mathrm{H}_{16} \mathrm{FeO}$ : C, 77.34; H, 4.15. Found: C, 76.98; H, 3.96.

4-Ferrocenylethynyl aniline (3c): Light orange solid; mp: $186-188{ }^{\circ} \mathrm{C}$. IR: $v\left(\mathrm{~cm}^{-1}\right)=820,1300$, 1580, $2353(\mathrm{C} \equiv \mathrm{C}), 3442,3359\left(\mathrm{NH}_{2}\right) .{ }^{1} \mathrm{H} \mathrm{NMR}\left(300 \mathrm{MHz}, \mathrm{CDCl}_{3}\right): \delta(\mathrm{ppm})=3.80\left(\mathrm{br} \mathrm{s}, 2 \mathrm{H}, \mathrm{NH}_{2}\right)$, 4.22 (pseudo t, $2 \mathrm{H}, J=3.6), 4.25$ (s, 5H), 4.48 (pseudo t, $2 \mathrm{H}, J=3.6), 6.65(\mathrm{~d}, 2 \mathrm{H}, J=8.6), 7.32$ (d, $2 \mathrm{H}, J=8.6) .{ }^{13} \mathrm{C} \mathrm{NMR}\left(125 \mathrm{MHz}, \mathrm{CDCl}_{3}\right): \delta(\mathrm{ppm})=66.18,68.50,69.90,71.21,85.58,86.15,113.45$, 114.77, 132.77, 146.16. Anal. Calcd for $\mathrm{C}_{18} \mathrm{H}_{15} \mathrm{FeN}$ : C, 71.79; H, 5.02; N, 4.65. Found: C, 72.08; $\mathrm{H}$, $4.83 ; \mathrm{N}, 4.72$.

3-Ferrocenylethynyl-1-trifluoromethyl benzene (3d): Orange solid; $\mathrm{mp}$ : $67-69{ }^{\circ} \mathrm{C}$. IR: $v\left(\mathrm{~cm}^{-1}\right)=$ $2215(\mathrm{C} \equiv \mathrm{C}) .{ }^{1} \mathrm{H}$ NMR $\left(500 \mathrm{MHz}, \mathrm{CDCl}_{3}\right): \delta(\mathrm{ppm})=4.28-4.30$ (pseudo s, 7H), $4.55(\mathrm{~s}, 2 \mathrm{H}), 7.46-7.75$ $(\mathrm{m}, 4 \mathrm{H}) .{ }^{13} \mathrm{C}$ NMR $\left(125 \mathrm{MHz}, \mathrm{CDCl}_{3}\right): \delta(\mathrm{ppm})=64.60,69.28,70.20,71.67,84.34,90.38,123.37(\mathrm{q}$, $\left.\mathrm{CF}_{3},{ }^{1} J_{\mathrm{CF}}=272 \mathrm{~Hz}, \mathrm{CF}_{3}\right), 124.08,124.95,128.08,128.78,130.92\left(\mathrm{q}, \mathrm{C},{ }^{2} J_{\mathrm{CF}}=32 \mathrm{~Hz}\right), 134.40$. Anal. Calcd for $\mathrm{C}_{19} \mathrm{H}_{13} \mathrm{~F}_{3} \mathrm{Fe}$ : C, 64.44; H, 3.70. Found: C, 64.70; H, 3.93.

\section{References}

1. Togni A. and Hayashi T. (1995) (Eds), Ferrocenes: Homogeneous catalysis, organic synthesis, materials science, $\mathrm{VCH}$, Weinheim.

2. Bard A. J., Denuault G., Lee C., Mandler D., and Wipf D. O. (1990) Scanning electrochemical microscopy - a new technique for the characterization and modification of surfaces. Acc. Chem. Res. 23, 357-363.

3. Brielbeck B., Frede M., and Steckhan E. (1994) Continuous electroenzymatic synthesis employing the electrochemical enzyme membrane reactor. Biocatalysis. 10, 49-64.

4. Kingston J. E., Ashford L., Beer P. D., and Drew M. G. B. (1999) Anion recognition and sensing by neutral and charged transition metal co-ordinated ferrocene phosphine amide receptors. J. Chem. Soc. Dalton. Trans. 2, 251-258.

5. Beer P. D., Cadman J., Llois J. M., Martınez-Manez R., Soto J., Pardo T., and Marcos M. D. (2000) Anion interaction with ferrocene-functionalised cyclic and open-chain polyaza and aza-oxa cycloalkanes, J. Chem. Soc. Dalton Trans. 1805-1812.

6. Valerio C., Alonso E., Ruiz J., Blais J.-C., and Astruc D. (1999) Ein polykationisches Metallodendrimer mit $24\left[\mathrm{Fe}\left(\eta^{5}-\mathrm{C}_{5} \mathrm{Me}_{5}\right)\left(\eta^{6}-N \text {-alkylanilin }\right)\right]^{+}$-Endgruppen zur Erkennung von Chlorid und Bromid, Angew. Chem. 111, 1855-1859.

7. Valerio C., Fillaut J.-L., Ruiz J., Guittard J., Blais J.-C., and Astruc D. (1997) The dendritic effect in molecular recognition: Ferrocene dendrimers and their use as supramolecular redox sensors for the recognition of small inorganic anions. J. Am. Chem. Soc. 119, 2588-2589.

8. Beer P .D., Keefe A. D., and Sikayika H. (1990) Metallocene bis(aza-crown ether) ligands and related compounds. Their syntheses, co-ordination chemistry, and electrochemical properties, J. Chem. Soc. Dalton Trans. 3289-3294.

9. Plenio H., Hermann J., and Leukel J. (1998) Synthesis of soluble 1,3-bridged ferrocene-acetylene polymers and the divergent-convergent synthesis of defined oligomers, J. Eur, Inorg. Chem. 20632069. 
10. Barlow S. and Hare D. O. (1997) Metal-metal interactions in linked metallocenes. Chem. Rev. 97, 637-670.

11. Rulkens R., Lough A. J., Manners I., Lovelace S. R., Grant C., and Geiger W. E. (1996) Linear oligo(ferrocenyldimethylsilanes) with between two and nine ferrocene units: Electrochemical and structural models for poly(ferrocenylsilane) high polymers, J. Am. Chem. Soc. 118, 12683-12695.

12. Albagi D., Bazan G., Wrighton M. S., and Schrock R. R. (1992) Well-defined redox-active polymers and block copolymers prepared by living ring-opening metathesis polymerization. J. Am. Chem. Soc. $114,4150-4158$.

13. Nguyen M. T. and Diaz A. F. (1994) Electrochemical and electrochromic properties of poly(dialkylsilyleneferrocenylene) films. Chem. Mater. 6, 952-954.

14. Audebert P., Calas P., Cerveau G., and Corriu R. J. P. (1994) Modified electrodes from organicinorganic hybrid gels containing ferrocene units covalently bonded inside a silica network. $J$. Electroanal. Chem. 372, 275-277.

15. Nlate S., Ruiz J., Blais J.-C., and Astruc D. (2000) Ferrocenylsilylation of dendrons: a fast convergent route to redox-stable ferrocene dendrimers. Chem. Commun. 417-418.

16. Zhang L., Godinez L. A., Lu T., Gokel G. W., and Kaifer A. E. (1995) Molekulare Erkennung an Grenzfl ächen: Bindung von Ferrocenylgruppen, die in einer Monoschicht verankert sind, durch eine amphiphile Calixaren-Wirtverbindung. Angew. Chem. 107, 236-239.

17. Raoof J. B., Ojani R., Hosseinzadeh R., and Ghasemi V. (2003) Electrocatalytic characteristics of a 1[4-(ferrocenyl ethynyl)phenyl]-1-ethanone modified carbon-paste electrode in the oxidation of ascorbic acid. Anal. Sci. 19, 1251-1258.

18. Ghasemi V., Raoof J. B., R., and Hosseinzadeh R. (2005) Voltammetric determination of ascorbic acid on a ferrocene derivative-modified carbon paste electrode, Bull. Electrochem. 21, 115-122.

19. Raoof J. B., Ojani R., Beitollahi H., and Hosseinzadeh R. (2006) Electrocatalytic determination of ascorbic acid at the surface of 2, 7-bis (ferrocenyl ethyl) fluoren-9-one modified carbon paste electrode. Electroanalysis. 18, 1193-1201.

20. Raoof J.B., Ojani R., Beitollahi H., and Hosseinzadeh R. (2006) Electrocatalytic oxidation and high selective voltammetric determination of L-cysteine at the surface of 1-[4-(ferrocenyl ethynyl]-1ethanone modified carbon paste electrode, Anal. Sci. 12, 1213-1220.

21. Salmanipour A., Taher M. A., Beitollahi H., and Hosseinzadeh R. (2013) New voltammetric strategy for simultaneous determination of $N$-acetylcysteine and folic acid using a carbon nanotube modified glassy carbon electrode, Colloids Surf. B 102, 385-390.

22. Shahmiri M. R., Bahari A., Karimi-Maleh H., Hosseinzadeh R., and Mirnia N. (2013) Ethynylferrocene - NiO/MWCNT nanocomposite modified carbon paste electrode as a novel voltammetric sensor for simultaneous determination of glutathione and acetaminophen, Sens. Actuators B 177, 70-77.

23. Wong W-Y., Ho K-Y., Ho S-L., and Lin Z. (2003) Carbon-rich organometallic materials derived from 4-ethynylphenylferrocene. J. Organomet. Chem. 683, 341-353.

24. Wong W-Y., Ho K-Y., and Choi K-H. (2003) New ferrocenyl heterometallic complexes of 2,7diethynylfluoren-9-one, J. Organomet. Chem. 670, 17-26.

25. Rosenblum M., Brawn N., Papenmeier J., and Applebaum M. (1966) Synthesis of ferrocenylacetylenes. J. Organomet. Chem. 6, 173-180.

26. Sonogashira K., Tohda Y., and Hagihara N. (1975) A convenient synthesis of acetylenes: catalytic substitutions of acetylenic hydrogen with bromoalkenes, iodoarenes and bromopyridines, Tetrahedron Lett. 16, 4467-4470.

27. Chinchilla R. snd Najera C. (2007) The Sonogashira reaction: a booming methodology in synthetic organic chemistry. Chem. Rev. 107, 874-922.

28. Doucet H. and Hierso J.-C. (2007) Palladium-based catalytic systems for the synthesis of conjugated enynes by Sonogashira reactions and related alkynylations. Angew. Chem. Int. Ed. 46, 834-871.

29. Sonogashira K. (1991) in: Comprehensive organic synthesis (Eds.: Trost B. M. and Fleming I.), Pergamon Press, Oxford, vol. 3, p 521.

30. Ojani R., Raoof J. B., and Norouzi B. (2008) Acetylferrocene modified carbon paste electrode; A sensor for electrocatalytic determination of hydrazine. Electroanalysis 20, 1378-1382.

31. Doisneau G., Balavoine G., Fillebine-Khan T. (1992) Synthesis and some reactions of ferrocenylacetylenes. J. Organomet. Chem. 425, 113-117. 